\title{
Early administration of keratinocyte growth factor improves $\beta$-cell regeneration in rat with streptozotocin-induced diabetes
}

\author{
Jamileh Movassat and Bernard Portha \\ Laboratoire de Physiopathologie de la Nutrition-CNRS/UMR 7059, Université Paris 7, 2, place Jussieu, 75005 Paris, France \\ (Correspondence should be addressed to J Movassat; Email: movassat@paris7.jussieu.fr)
}

\begin{abstract}
The aim of our study was to investigate the ability of keratinocyte growth factor (KGF; palifermin) in regulating $\beta$-cell growth in normal newborn rats and in rats with neonatal diabetes. Wistar rats were injected with streptozotocin (STZ) to induce diabetes on the day of birth. From days 2 to 6 after birth, animals received a daily s.c. injection of KGF (STZ/KGF group) and the dose of $3 \mathrm{mg} / \mathrm{kg}$ body weight or saline solution (STZ groups). A group of non-diabetic Wistar rats was treated either with saline (Wistar group) or with KGF from days 2 to 6 after birth at the dose of $3 \mathrm{mg} / \mathrm{kg}$ body weight (Wistar/KGF group). $\beta$-cell mass was measured at day 7 after birth in all groups. $\beta$ - and ductal cells replication were measured in all groups and apoptosis was assessed in the pancreas of 2-, 4-, and 7-day-old STZ and STZ/KGF rats. The total $\beta$-cell mass of the 7-day-old KGF/STZ neonates was significantly increased compared with that of age-matched STZ rats. $\beta$-cell replication rate was decreased at day 2 in the
\end{abstract}

STZ/KGF group and was similar in the 4- and 7-day-old rats from STZ and STZ/KGF groups. Duct cell replication was significantly increased in the pancreas of 2- and 4-day-old KGF/STZ neonates when compared with that of age-matched rats from STZ control group. The rate of apoptosis in the neonatal pancreases of STZ and KGF/STZ groups was not significantly different. In non-diabetic Wistar rats, KGF treatment led to a slight but significant increase in duct cell proliferation at day 2 without significant changes in the total $\beta$-cell mass in the 7-dayold rats. We provide evidence for a growth-promoting effect of KGF during $\beta$-cell regeneration in neonatal diabetic rats. KGF exerts strong mitogenic effect on the pancreatic duct cells, thus expanding the population of precursor cells that subsequently differentiate into insulin-producing $\beta$-cells.

Journal of Endocrinology (2007) 195, 333-340

\section{Introduction}

Endocrine pancreatic cells, although highly specialized, retain the capacity to regenerate upon severe damage. One of the suitable models for the study of the regenerative potential of pancreatic $\beta$-cells is the neonatal diabetes induced by streptozotocin (n-STZ; Portha et al. 1974). We have previously reported that the damage caused by STZ in the pancreas of newborn rats is followed by the recovery of the neonatal diabetes due to the spontaneous regeneration of insulin-producing cells (Movassat et al. 1997). In this model of $\beta$-cell regeneration, $\beta$-cell mass can be modulated by different factors, mainly hormones and growth factors (Movassat et al. 1997, Irako et al. 2006).

Keratinocyte growth factor (KGF also called FGF-7) is a member of the heparin-binding fibroblast growth factor family. The peptide, originally isolated from the conditioned medium of a human embryonic lung fibroblast cell line (Rubin et al. 1989), shows a high degree of specificity for epithelial cells. KGF is known to mediate cell proliferation and differentiation in a variety of tissues and organs including the gastrointestinal tract (Housley et al. 1994), dermis (Werner et al. 1992), and lung epithelia (Ulich et al. 1994). In the pancreas, KGF and its receptor are upregulated in pancreatic carcinomas (Ishiwata et al. 1998) and ectopic expression of KGF in $\beta$-cells resulted in intra-islet duct cell proliferation (Krakowski et al. 1999). Moreover, KGF stimulates differentiation of endocrine precursor cells isolated from human fetal pancreas into $\beta$-cells (Movassat et al. 2003). Here, we investigated the impact of an early treatment of non-diabetic and diabetic rat neonates with KGF (palifermin) on the regulation of $\beta$-cell growth and regeneration.

\section{Materials and Methods}

\section{Animals}

Wistar rats were fed ad libitum with pelleted chow (diet 113, SAVE, Villemoisson-sur-Orge, France). Females were caged with males for one night and pregnancy was detected by abdominal palpation after 14 days. Natural birth occurred 22 days after mating.

Four experimental groups were studied.

Wistar group In this group, from days 2 to 6 , rats received daily s.c. injection of saline solution. 
Wistar/KGF group In this group, from days 2 to 6 after birth, rats received daily s.c. injection of KGF (palifermin) provided by AMGEN (Thousand Oaks, CA, USA) at the dose of $3 \mathrm{mg} / \mathrm{kg}$ body weight.

STZ group On the day of birth, rats of this group received an injection of $100 \mu \mathrm{g} / \mathrm{g}$ body weight of STZ (Sigma) freshly dissolved in citrate buffer $(0.05 \mathrm{M}, \mathrm{pH} 4 \cdot 5)$. From days 2 to 6 , rats received a daily s.c. injection of saline solution.

STZ/KGF group On the day of birth, rats of this group received a single daily i.p. injection of $100 \mu \mathrm{g} / \mathrm{g}$ body weight of STZ freshly dissolved in citrate buffer $(0 \cdot 05 \mathrm{M}, \mathrm{pH} 4 \cdot 5)$. From days 2 to 6 (during 5 days), rats received daily s.c. injection of KGF (palifermin) single i.p. provided by AMGEN at the dose of $3 \mathrm{mg} / \mathrm{kg}$ body weight.

In each group, the pups were left with their own mother and kept in an environment of constant temperature, humidity, and day-night cycle. The number of animals per litter was kept at eight. For each experimental group (Wistar, Wistar/KGF, STZ, and $\mathrm{KGF} / \mathrm{STZ}$ groups), the pups belonged to at least three different litters. In diabetic groups (STZ and KGF/STZ groups), all the neonates were tested for blood glucose concentration (Glucotrend, Roche) $24 \mathrm{~h}$ after STZ administration. Animals were included in the study only if their glycemia was higher than $1 \cdot 8 \mathrm{~g} / 1$.

Plasma glucose levels and body weight were measured in the 2-, 4-, and 7-day-old rats.

Animals were killed on days 2, 4, or 7 after birth. One hour before killing, animals were given an i.p. injection of $5^{\prime}$-bromo$2^{\prime}$-deoxyuridine (BrdU; Sigma) at the dose of $50 \mathrm{mg} / \mathrm{kg}$.

\section{Immunohistochemistry}

Pancreases were removed, weighed, and fixed in aqueous Bouin's solution for $24 \mathrm{~h}$ and embedded in Paraplast.

Each pancreas was serially sectioned $(5 \mu \mathrm{m})$ throughout its length to avoid any bias due to regional changes in islet distribution and islet cell composition.

Sections at a fixed interval throughout the block (every 35th section) were immunostained for insulin using an indirect peroxidase labeling technique as described previously (Michel et al. 1982). The primary antibody was an anti-insulin serum raised in guinea pig (ICN Biomedicals, Orsay, France), and the secondary antibody was a peroxidase-conjugated rabbit anti-guinea pig IgG (Dako, Trappes, France).

In the sections stained for insulin, the number of isolated $\beta$-cells located in the duct epithelium was evaluated in the 7-day-old rats of the STZ and STZ/KGF groups. Results were expressed as the percentage of insulin-containing cells within the duct epithelium over the total number of ductal cells in the sections.

\section{Morphometry}

Quantitative evaluation of total $\beta$-cell area was performed in the 7-day-old neonates using a computer-assisted image analysis system based on an Olympus BX40 microscope connected via a video camera to a PC and using the Visiolab 1000 software (Biocom, Les Ulis, France). In each section, the area of insulin-positive cells, as well as the total pancreatic area, was measured. The relative $\beta$-cell area in the pancreas was determined by stereological morphometric methods, calculating the ratio between the area occupied by the insulinpositive cells and that occupied by the total pancreatic tissue. At least eight sections were analyzed for each pancreas. For the calculation of $\beta$-cell mass, the ratio between the area occupied by insulin-positive cells and that occupied by the total pancreatic tissue was multiplied by the total pancreas weight.

\section{$\beta$-cell apoptosis}

Apoptotic cells in the pancreatic sections from STZ and STZ/KGF rats were detected by TdT-dependent dUTP-biotin nick end labelling (TUNEL) assay using the ApopTag peroxidase in situ apoptosis detection kit (Chemicon, Molsheim, France) according to the manufacturer's instructions. Sections were then immunostained for insulin using the indirect method with an anti-guinea pig alkaline phosphatase-conjugated secondary antibody (ICN Biomedicals).

\section{$\beta$-cell and duct cell replication}

BrdU staining was performed using the cell proliferation kit (Amersham), as described previously (Movassat et al. 1997). After BrdU staining, sections were stained for insulin using the indirect method with an anti-guinea pig alkaline phosphataseconjugated secondary antibody (ICN Biomedicals).

To estimate $\beta$ - or ductal cell replication rates, $\beta$ - or ductal cells were counted in double-stained pancreatic sections using an Olympus BX40 microscope. Results were expressed as the percentage of BrdU-positive $\beta$ - or ductal cells. At least 300 (days 2 and 4) or 500 (day 7) $\beta$-cells and 800 ductal cells were counted per pancreas, and four different sections were analyzed for each pancreas.

\section{Individual $\beta$-cell area}

$\beta$-cell size was determined in the 7-day-old neonates from the STZ and STZ/KGF groups on insulin-stained sections by evaluating the mean cross-sectional area of individual $\beta$-cells. $\beta$-cell nuclei of random sections were counted and the area of $\beta$-cell in the sections was measured by planimetry as described previously. The $\beta$-cell area was divided by the number of nuclei to calculate the area of individual $\beta$-cells.

\section{Statistical analysis}

Values are expressed as means \pm s.E.M. The significance of differences between mean values was evaluated by Student's $t$-test. $P<0.05$ was considered significant. 


\section{Results}

Body weight, pancreas weight, and plasma glucose levels in the 2-, 4-, and 7-day-old neonates

As shown in Table $1, \mathrm{KGF}$ treatment did not significantly alter the body weight in the 2-, 4-, and 7-day-old STZ/KGF neonates. The pancreas weight was slightly but significantly increased in the 7-day-old KGF-treated rats compared with STZ rats $(P<0 \cdot 05)$.

Regarding the plasma glucose levels, a significant decrease and a slight but significant increase in the plasma glucose levels were observed on days 2 and 4 respectively in the KGF-treated group $(P<0 \cdot 05)$. The changes in the plasma glucose levels observed during the first days after STZ administration could be due to the different levels of cell destruction leading to the release of insulin content of destructed $\beta$-cells, but this is transient since at day 7 , the plasma glucose level was similar between KGF-treated and untreated STZ newborns. No significant differences were observed in the body weight, pancreas weight, and plasma glucose levels between the Wistar and Wistar/KGF groups (Table 1).

\section{Morphological aspect of the endocrine pancreas in KGF/STZ rats}

Immunolocalization of the insulin-producing cells using specific anti-insulin antibody revealed larger areas occupied by the $\beta$-cells in the pancreatic sections from KGF/STZ animals at day 7 after birth (Fig. 1B) compared with those observed in the STZ rats (Fig. 1A). The number of isolated $\beta$-cells located in the duct epithelium was significantly higher in the pancreas of 7-day-old newborns treated with KGF $(2 \cdot 58 \pm 0 \cdot 30 \%)$ compared with that of age-matched STZ control group $(1 \cdot 51 \pm 0 \cdot 31 \%)$. There were no noticeable differences in the morphological aspect of the endocrine pancreas between the Wistar (Fig. 3A) and Wistar/KGF groups (Fig. 3B).
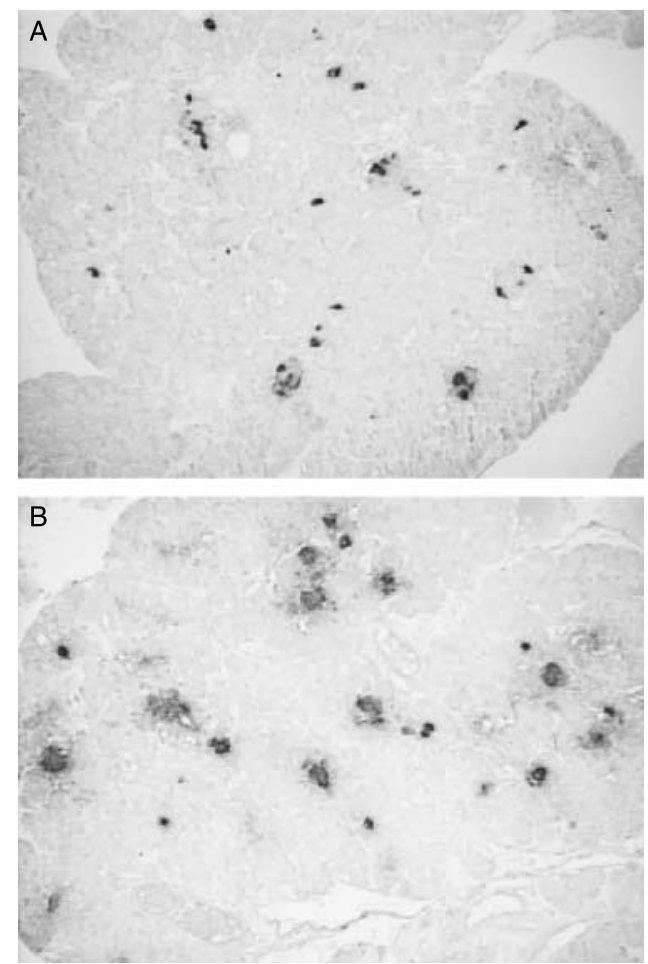

Figure 1 Immunoperoxidase staining for insulin in pancreatic sections from 7-day-old (A) STZ and (B) STZ/KGF newborns. $\beta$-cells have brown cytoplasm $(\times 62)$.

\section{Morphometrical quantification of pancreatic $\beta$-cells in} $\mathrm{KGF} / \mathrm{STZ}$ rats

The relative area of $\beta$-cells over the area of the total pancreatic tissue was significantly increased $(P<0 \cdot 01)$ in the 7-day-old STZ/KGF-treated $(0.92 \pm 0.06 \%)$ rats compared with the control STZ group $(0 \cdot 56 \pm 0 \cdot 06 \%)$.

Table 1 Characteristics of 2-, 4-, and 7-day-old neonates from the streptozotocin (STZ), STZ/keratinocyte growth factor (KGF), W, and W/KGF groups

\begin{tabular}{|c|c|c|c|}
\hline Group & Body weight (g) & Pancreas weight $(\mathrm{mg})$ & Plasma glucose levels $(\mathrm{mmol} / \mathrm{l})$ \\
\hline STZ & $8 \cdot 3 \pm 0 \cdot 2(n=6)$ & $15 \cdot 7 \pm 1 \cdot 6(n=6)$ & $14 \cdot 3 \pm 1 \cdot 1(n=6)$ \\
\hline STZ/KGF & $7 \cdot 9 \pm 0 \cdot 1(n=8)$ & $16 \cdot 9 \pm 1 \cdot 9(n=8)$ & $9 \cdot 9 \pm 0 \cdot 5^{+}(n=8)$ \\
\hline W & $8 \cdot 7 \pm 0 \cdot 4(n=8)$ & $17 \cdot 0 \pm 1 \cdot 1(n=8)$ & $6 \cdot 1 \pm 0 \cdot 3(n=5)$ \\
\hline W/KGF & $9 \cdot 29 \pm 0 \cdot 3(n=8)$ & $16 \cdot 8 \pm 1 \cdot 8(n=8)$ & $6 \cdot 5 \pm 0 \cdot 7(n=5)$ \\
\hline STZ & $9 \cdot 8 \pm 0 \cdot 5(n=6)$ & $30 \cdot 4 \pm 2 \cdot 0(n=6)$ & $14 \cdot 8 \pm 1 \cdot 6(n=6)$ \\
\hline STZ/KGF & $9 \cdot 3 \pm 0 \cdot 3(n=8)$ & $23 \cdot 7 \pm 4 \cdot 1(n=8)$ & $23 \cdot 1 \pm 2 \cdot 2 *(n=8)$ \\
\hline W & $11 \cdot \overline{6} \pm 0 \cdot 26(n=8)$ & $32 \cdot 8 \pm 1 \cdot 3(n=4)$ & $6 \cdot 2 \pm 0 \cdot 2(n=11)$ \\
\hline W/KGF & $12 \cdot 4 \pm 0 \cdot 4(n=11)$ & $37 \cdot 7 \pm 3 \cdot 37(n=4)$ & $5 \cdot 8 \pm 0 \cdot 2(n=4)$ \\
\hline STZ & $14 \cdot 1 \pm 1 \cdot 3(n=10)$ & $41 \cdot 3 \pm 1 \cdot 7(n=10)$ & $10 \cdot \overline{5} \pm 2 \cdot 2(n=10)$ \\
\hline STZ/KGF & $16 \cdot 5 \pm 0 \cdot 9 *(n=8)$ & $50 \cdot 0 \pm 3 \cdot 8 *(n=8)$ & $8 \cdot 8 \pm 2 \cdot 7(n=8)$ \\
\hline W & $17 \cdot 8 \pm 0 \cdot 2(n=8)$ & $45 \cdot 5 \pm 1 \cdot 6(n=6)$ & $6 \cdot 8 \pm 0 \cdot 1(n=8)$ \\
\hline W/KGF & $18 \cdot 4 \pm 0 \cdot 2(n=6)$ & $51 \cdot 6 \pm 2 \cdot 9(n=6)$ & $6 \cdot 4 \pm 0 \cdot 2(n=5)$ \\
\hline
\end{tabular}

Values are expressed as mean \pm s.E.M. $n$, number of animals; W, Wistar; W/KGF, Wistar/KGF. The significance of differences between mean values was evaluated by Student's $t$ test. ${ }^{*} P<0 \cdot 05$ and ${ }^{+} P<0 \cdot 01$ between the STZ and STZ/KGF groups. 


\section{$\square$ STZ \\ STZ/KGF \\ Wistar \\ \$ Wistar/KGF}

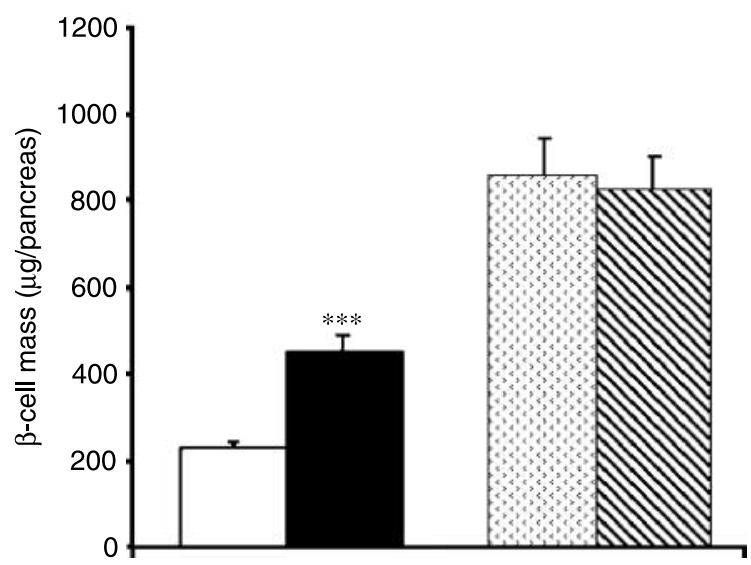

Figure 2 Total $\beta$-cell mass ( $\mu \mathrm{g} /$ pancreas) of 7 -day-old Wistar, Wistar/KGF, STZ, and STZ/KGF newborns. ${ }^{* * *} P<0 \cdot 001$ when compared with the STZ group. $\beta$-cell mass was calculated by multiplying the pancreas weight by the ratio of the $\beta$-cell area over the total pancreatic tissue area.

When expressed as the total $\beta$-cell mass ( $\mu \mathrm{g} /$ pancreas), we found a twofold increase in this parameter in STZ neonates treated with KGF during 5 days (days 2-6 included) when compared with STZ control animals (Fig. 2).

The relative $\beta$-cell area over the area of the total pancreatic tissue was similar in the non-diabetic Wistar rats $(1.96 \pm$ $0 \cdot 26 \% ; n=4)$ compared with KGF-treated Wistar rats $(1 \cdot 69 \pm 0 \cdot 23 \% ; n=4$; Fig. 3). The total $\beta$-cell mass in the pancreas was not significantly different in the KGF-treated Wistar group compared with the untreated Wistar group (Fig. 2).

\section{$\beta$-cell replication in STZ/KGF rats}

In order to determine whether the increase of $\beta$-cell mass in the STZ/KGF group compared with that of the STZ group was due to an enhancement of $\beta$-cell replication, we evaluated the rate of mitotic $\beta$-cells in the $2-, 4-$, and 7-day-old neonates by double staining of the pancreatic sections for insulin and the S-phase marker BrdU (Fig. 4).

$\beta$-cell proliferation index was determined by calculating the percentage of $\mathrm{BrdU}$-positive $\beta$-cells over the total number of $\beta$-cells in the pancreas sections.

The $\beta$-cell proliferation index was similar in the 4- and 7-day-old neonates from the STZ and STZ/KGF groups (Fig. 5). Surprisingly, at the age of 2 days postnatal, we found a lower mitotic index of $\beta$-cells in the STZ/KGF group compared with the STZ group (Fig. 5).

We evaluated $\beta$-cell replication in the 2 -day-old Wistar and Wistar/KGF rats. The mitotic index of $\beta$-cells in those groups
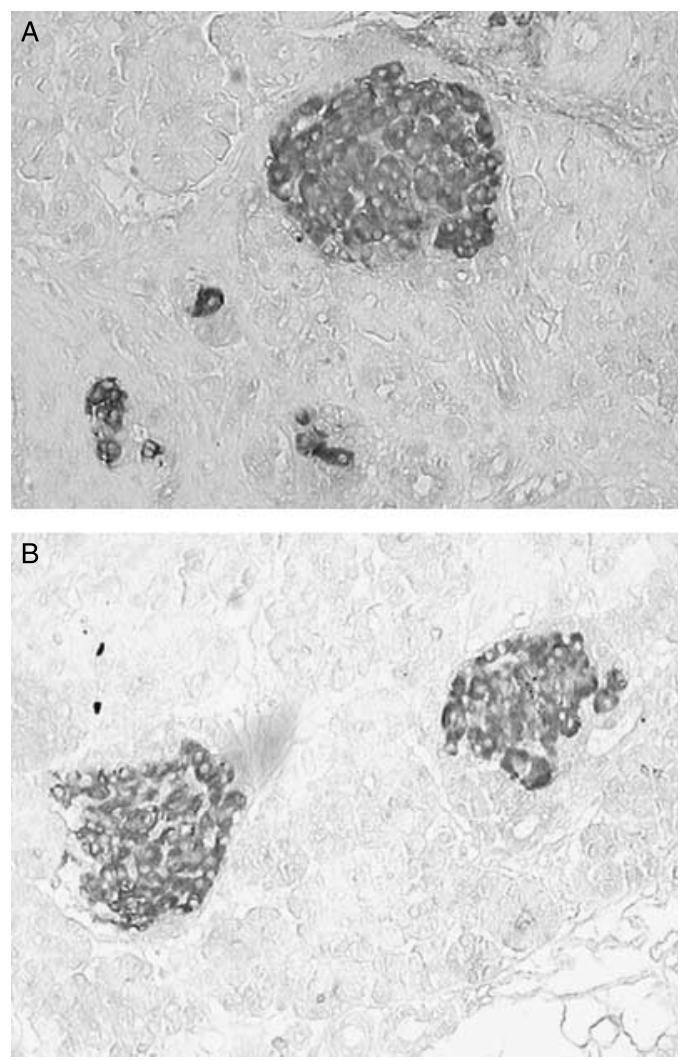

Figure 3 Immunoperoxidase staining for insulin in pancreatic sections from 7-day-old (A) Wistar and (B) Wistar/KGF newborns. $\beta$-cells have brown cytoplasm $(\times 125)$.

was $8 \cdot 2 \pm 0 \cdot 6 \%(n=4)$ and $7 \cdot 5 \pm 0 \cdot 4 \%(n=4)$ respectively, which was not statistically significant.

\section{Ductal cell replication}

The mitogenic effect of KGF on the ductal cells was assessed in the pancreases of 2-, 4-, and 7-day-old neonates from the STZ and STZ/KGF groups. Ductal cell proliferation rate was determined by calculating the percentage of BrdU-positive ductal cells over the total number of ductal cell in the pancreatic sections. In the KGF-treated group, the rate of replicating duct cells was significantly higher in the 2- and 4-day-old newborns treated with KGF (Fig. 6) when compared with the untreated STZ rats. In the 7-day-old animals, this parameter was similar between the two groups (Fig. 6).

Since KGF seemed to act specifically on ductal cells in diabetic rats, we also evaluated the rate of ductal cell replication in the 2-day-old Wistar and Wistar/KGF rats. We found a slight but significant $(P<0 \cdot 05)$ increase in the percentage of BrdU-positive ductal cells in the Wistar/KGF group $(5 \cdot 38 \pm 0 \cdot 39 \% ; n=5)$ compared with the untreated Wistar group $(4 \cdot 08 \pm 0 \cdot 38 \% ; n=5)$. 

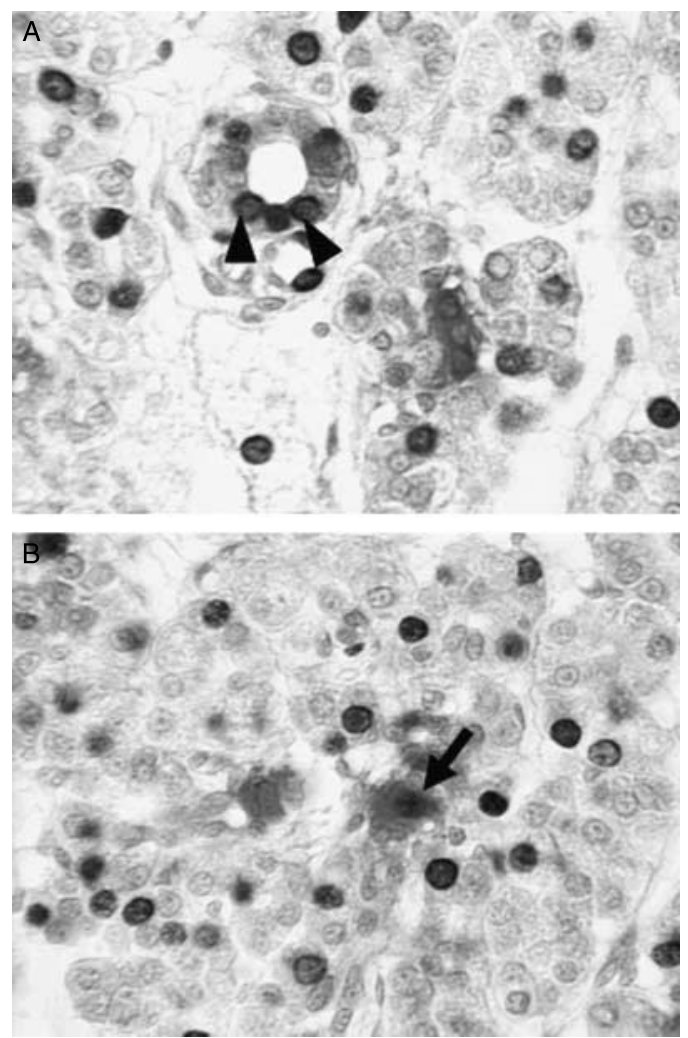

Figure 4 Double staining for $\mathrm{BrdU}$ (brown) and insulin (red) of pancreatic sections from (A) 2-day-old STZ and (B) STZ/KGF newborns. (A) Arrowheads show BrdU-positive ductal cell.

(B) Arrow shows BrdU-positive $\beta$-cells $(\times 250)$.

\section{$\beta$-cell apoptosis}

We looked for apoptotic cells in the pancreas of the 2-, 4-, and 7 -day-old neonates from our two diabetic groups. In both STZ and STZ/KGF groups, and at all ages, the rate of $\beta$-cell apoptosis as well as acinar and ductal cell apoptosis was extremely low in the pancreatic sections (Fig. 7). We quantified the number of apoptotic $\beta$-cells in the pancreases of 2-day-old neonates from the STZ and STZ/KGF groups.

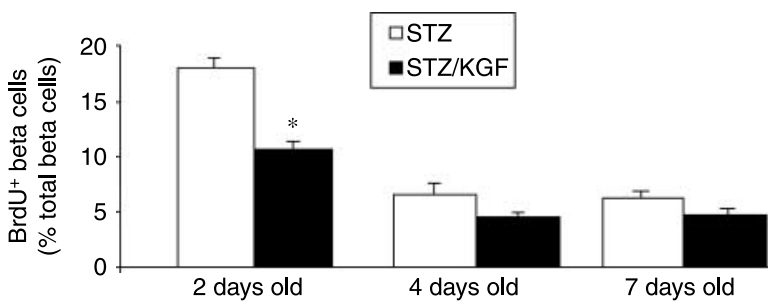

Figure 5 BrdU labeling index of $\beta$-cells in the 2-, 4-, and 7-day-old STZ and KGF/STZ rats. ${ }^{*} P<0 \cdot 05$ when compared with the 2 -dayold STZ group. Results are expressed as the percentage of BrdUpositive $\beta$-cells. At least 300 (days 2 and 4) or 500 (day 7) $\beta$-cells were counted per pancreas.

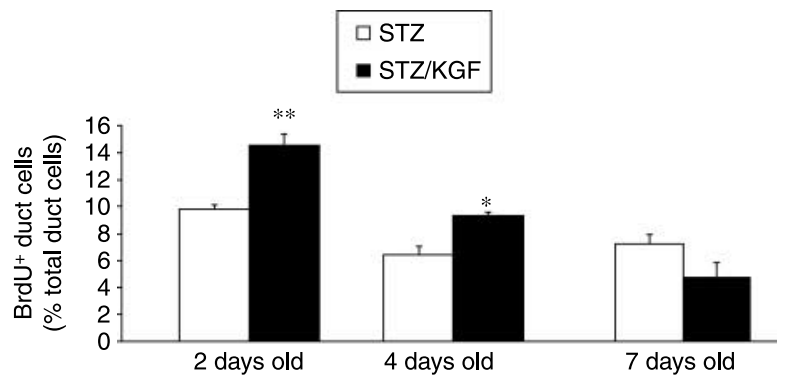

Figure 6 BrdU labeling index of ductal cells in the 2-, 4-, and 7-dayold STZ and KGF/STZ rats. ${ }^{*} P<0.05$ and ${ }^{* *} P<0.01$ when compared with the age-matched STZ group. Results are expressed as the percentage of BrdU-positive ductal cells. At least 800 ductal cells were counted per pancreas.

At day 2 after birth, in two pancreases from the STZ group and three pancreases from the STZ/KGF group, we did not detect any apoptotic $\beta$-cell. In two pancreases from the STZ group, we found 2 apoptotic $\beta$-cells out of 420 and 505 $\beta$-cells respectively, and in one pancreas from the STZ/KGF group there were 3 apoptotic $\beta$-cells out of $600 \beta$-cells.
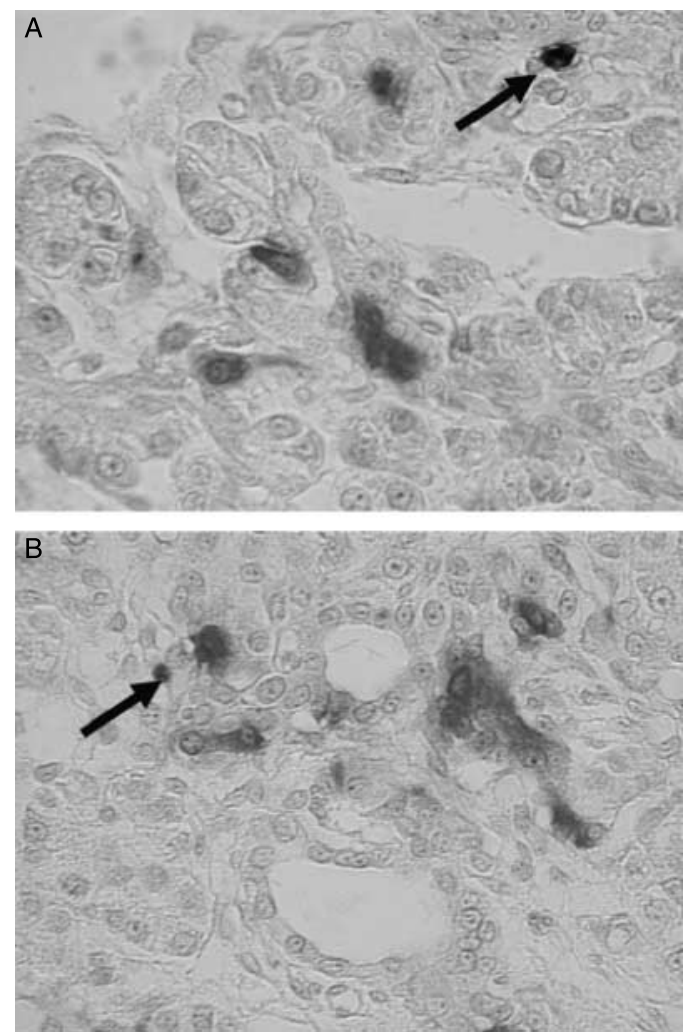

Figure 7 Double staining for apoptosis (TUNEL method) and insulin of pancreatic sections from the 2-day-old (A) STZ and (B) KGF/STZ rats. Apoptotic nuclei are in brown. $\beta$-cells have red cytoplasm. Arrows show apoptotic acinar cells (brown; $\times 520)$. 


\section{Discussion}

The STZ-induced neonatal diabetes (n-STZ) is a valuable model for the study of regenerative potential of pancreatic $\beta$-cells. The partial and spontaneous recovery of $\beta$-cell mass after the damage induced by STZ can be modulated by specific agents, providing an interesting in vivo system for the investigation of growth-promoting effect of factors aimed at the expansion of $\beta$-cell mass as a therapy for diabetes in the context of restricted $\beta$-cell number. Here, we show a positive regulatory effect for KGF on $\beta$-cell regeneration in diabetic newborn rats. After the 5-day course of the treatment, the total weight of the pancreas and the proportion of $\beta$-cells in the pancreas were significantly increased. Since no significant hypertrophy of $\beta$-cell was detected as evidenced by the measurement of the individual $\beta$-cell area $\left(89 \pm 6 \mu \mathrm{m}^{2}\right.$ in the STZ group and $99 \pm 7 \mu \mathrm{m}^{2}$ in the STZ/KGF group), we concluded that KGF induced the increase in $\beta$-cell number. The total $\beta$-cell mass in the pancreas of KGF/STZ rats after daily injection of KGF during 5 days was two times higher than that of STZ rats. This significant effect was comparable in terms of amplitude to the growth-promoting effect of glucagon-like peptide-1 (GLP 1) that induced the stimulation of $\beta$-cell regeneration in the STZ diabetic neonates to a similar extent (Tourrel et al. 2001).

The number of $\beta$-cells in the pancreas is determined by the balance between cell death and new cell formation. We first investigated the effect of KGF in the prevention of $\beta$-cell apoptosis in the pancreas of STZ/KGF rats. Anti-apoptotic effects of KGF on various tissues such as epidermal cells (Jeschke et al. 2002), neural cells (Sadohara et al. 2001), and hepatocytes (Senaldi et al. 1998) have been described in numerous studies. It is known that STZ induces $\beta$-cell death partly by stimulation of apoptosis (Yamamoto et al. 1981, Cardinal et al. 2001). We hypothesized that KGF by its antiapoptotic effect could prevent $\beta$-cell death in the pancreas of diabetic animals after administration of STZ, and thus be partly accountable for the increase in $\beta$-cell number observed in the STZ/KGF group. We therefore evaluated the rate of apoptosis by TUNEL assay in the pancreas of $2-, 4-$, and 7-day-old STZ and STZ/KGF rats. At all ages, the number of apoptotic cells in the pancreas was extremely low and similar between the two groups, suggesting that in these experimental conditions, the anti-apoptotic effect of KGF described in other cell systems does not operate in the n-STZ model. This could be explained partly by the fact that in adult rats, STZ-induced apoptosis occurs within few hours after STZ administration (Morimoto et al. 2005). In our protocol, the first injection of KGF was given $24 \mathrm{~h}$ after STZ administration and therefore without effect on the prevention of the early phase of $\beta$-cell apoptosis induced by STZ.

The newly formed $\beta$-cells can be generated by the replication of existing $\beta$-cells and/or by differentiation of endocrine precursor cells into $\beta$-cells. In order to determine whether KGF acts by stimulating $\beta$-cell replication, we next evaluated the percentage of dividing $\beta$-cells in the pancreas of KGF-treated rats and control STZ rats. Our data on $\beta$-cell replication showed that the number of mitotic $\beta$-cells was not significantly different between the STZ and STZ/KGF groups at days 4 and 7, and even lower in STZ/KGF rats at day 2 , ruling out the stimulation of the replication of preexisting $\beta$-cell as the major mechanism induced by KGF in this model. In the normal pancreas of Wistar rats, KGF did not stimulate $\beta$-cell replication as evidenced by the similar rate of $\beta$-cell replication at day 2 in the Wistar and Wistar/KGF groups. In contrast, a significant mitogenic effect of KGF on ductal cells in the 2- and 4-day-old newborn treated with the peptide compared with the control STZ group was evident. In keeping with these results, several authors previously implicated KGF in ductal cell proliferation. Daily administration of KGF in adult rats (Yi et al. 1994) increased the mitotic activity of ductal cells and a higher percentage of dividing ductal cells was evident in the pancreas of transgenic mice overexpressing KGF (Krakowski et al. 1999). In those works, the effects of KGF were assessed in non-diabetic animals without $\beta$-cell deficiency. They revealed significant duct cell proliferation induced by KGF associated with modest or no increase in $\beta$-cell mass. This was also confirmed by our present data on the effects of KGF on normal neonatal pancreas, showing that KGF treatment in non-diabetic Wistar neonates with normal $\beta$-cell mass did not lead to the increase in $\beta$-cell mass despite the stimulation of ductal cell proliferation at day 2 . Interestingly, in our study in the STZ diabetic group, the mitogenic effect of KGF on ductal cells was associated with significant increase in $\beta$-cell mass due to $\beta$-cell differentiation. A possible explanation for the greater effect of KGF on $\beta$-cell differentiation in diabetic rats is the context of restricted $\beta$-cell mass in those rats, which implies the activation of several interconnected compensatory mechanisms in the pancreas in order to regulate cell homeostasis. In keeping with this idea, we have previously shown that KGF administration to nude rats bearing transplant composed of fetal endocrine pancreatic precursor cells led to the increase in the total number of $\beta$-cells in the graft without increasing the $\beta$-cell number within the pancreas of adult non-diabetic rats (Movassat et al. 2003). In order to elucidate whether KGF is able to stimulate $\beta$-cell growth in neonatal rats with spontaneous $\beta$-cell deficiency, we are currently investigating the effect of an early postnatal treatment of Goto-Kakizaki rats with KGF on the $\beta$-cell growth. These rats have their $\beta$-cell mass reduced by $50 \%$ compared with age-matched Wistar rats (Movassat \& Portha 1999) and exhibit a specific deficiency in $\beta$-cell neogenesis.

The proliferation and differentiation of pancreatic duct cells have been implicated in islet regeneration in the experimental models of diabetes in rodents (Sarvetnick et al. 1990, Sharma et al. 1999, Plachot et al. 2001). In those models, proliferation of pancreatic duct cells leads to an increase in the number of endocrine precursor cells that could ultimately differentiate into $\beta$-cells. Moreover, in pathological states such as 
pancreatic duct carcinomas, proliferation of ductal cells leads to islet neogenesis (Dawiskiba et al. 1992, Terada et al. 1997). Treatment of embryonic pancreatic rudiments with KGF stimulated the proliferation of epithelial progenitor cells (Elghazi et al. 2002). Interestingly, in our experiments, it appears clearly that the activation of duct cell proliferation is an early event which is evident in the pancreas of 2-day-old STZ neonates treated with KGF. Thereafter, duct cell proliferation decreases gradually but still remains higher in the KGF-treated group at day 4 . The activation of duct cell proliferation precedes the increase in $\beta$-cell mass induced by KGF at day 7 . The higher number of single $\beta$-cell located in the duct epithelium in the KGF-treated group suggests that a subset of proliferating ductal cells acquires $\beta$-cell phenotype, thus participating in the increase of $\beta$-cell mass in the KGFtreated group. The intracellular mechanisms involved in the KGF-induced duct cell proliferation and $\beta$-cell differentiation are under investigation in our laboratory. Finally, in a work by Krakowski and colleagues, it has been shown that the expression of KGF in the pancreas leads to ductal cell proliferation, as it was the case in our study, but also to isletto-hepatocyte differentiation within the pancreas of transgenic mice (Krakowski et al. 1999). In order to determine whether such a transdifferentiation is induced by KGF in the pancreas of diabetic neonates during the process of $\beta$-cell regeneration, we carefully examined the pancreatic sections of STZ rats and KGF-treated STZ rats in the search for hepatocyte-like cells. The sections were stained with hematoxylin and eosin and morphologically compared with hematoxylin-eosin-stained sections of liver from agematched rat neonates (data not shown). We could not find any evidence of the presence of hepatocyte-like cells within the pancreas of neither KGF/STZ rats nor STZ rats. Therefore, we believe that in our model of regeneration, in contrast to Krakowski's study, KGF does not induce pancreato-hepatic transdifferentiation. In conclusion, we provide evidence for a growth-promoting effect of KGF during $\beta$-cell regeneration in neonatal diabetic rats, which does not alter $\beta$-cell growth in non-diabetic Wistar rats. Our data establish that in STZ diabetic rats, KGF exerts strong mitogenic effect on the pancreatic ductal cells, thus expanding the population of precursor cells that subsequently differentiate into insulin-producing $\beta$-cells. From the present study and other works (reviewed in Hardikar 2004), it emerges that the pancreas can sense the mass of functional $\beta$-cells and institute regenerative processes that lead to restoration of $\beta$-cell mass. In animal models of $\beta$-cell mass restriction, pharmacological approaches have been proved to be able to efficiently stimulate the compensatory growth of $\beta$-cells (reviewed in Bouwens \& Rooman 2005). Here, we report that KGF might be considered as a potent regenerationpromoting factor with exclusive effects on the activation of $\beta$-cell differentiation. Should this kind of approach work satisfactorily in humans, it could hold great promise for the development of novel strategies for the cure of diabetes associated with restricted $\beta$-cell mass.

\section{Acknowledgements}

We thank AMGEN Inc. for providing KGF (palifermin) used in this study. We warmly thank E Kebaili and A Ilias for excellent technical assistance. The authors are supported by grants from the Centre National de la Recherche Scientifique/CNRS. The authors declare that there is no conflict of interest that would prejudice the impartiality of this scientific work.

\section{References}

Bouwens L \& Rooman I 2005 Regulation of pancreatic beta cell mass. Physiological Reviews 85 1255-1270.

Cardinal JW, Margison GP, Mynette KJ, Yates AP, Cameron DP \& Elder RH 2001 Increased susceptibilty to streptozotocin-induced beta-cell apoptosis and delayed autoimmune diabetes in alkylpurine-DNA-N-glycosylase deficient mice. Molecular and Cellular Biology 21 (16) 5606-5613.

Dawiskiba S, Pour PM, Stenram U, Sundler F \& Andren-Sandberg A 1992 Immunohistochemical characterization of endocrine cells in experimental exocrine pancreatic cancer in the Syrian golden hamster. International Journal of Pancreatology 11 87-96.

Elghazi L, Cras-Meneur C, Czernichow P \& Scharfmann R 2002 Role for FGFR2IIIb-mediated signals in controlling pancreatic endocrine progenitor cell proliferation. PNAS 99 3884-3889.

Hardikar AA 2004 Generating new pancreas from old. Trends in Endocrinology and Metabolism 15 198-203.

Housley RM, Morris CF, Boyle W, Ring B, Biltz R, Tarpley JE, Aukerman SL, Devine PL, Whitehead RH \& Pierce GF 1994 Keratinocyte growth factor induces proliferation of hepatocytes and epithelial cells throughout the rat gastrointestinal tract. Journal of Clinical Investigation 94 1764-1777.

Irako T, Akamizu T, Hosoda H, Iwakura H, Haryazu H, Tojo K, Tajima N \& Kangawa K 2006 Ghrelin prevents development of diabetes at adult age in streptozotocin-treated newborn rats. Diabetologia 49 1264-1273.

Ishiwata T, Friess H, Buchler MW, Lopez ME \& Korc M 1998 Characterization of keratinocyte growth factor and receptor expression in human pancreatic cancer. American Journal of Pathology 153 213-222.

Jeschke MG, Richter G, Hofstadter F, Herndon DN, Perez-Polo JR \& Jauch KW 2002 Non-viral liposomal keratinocyte growth factor (KGF) cDNA gene transfer improves dermal and epidermal regeneration through stimulation of epithelial and mesenchymal factors. Gene Therapy 9 1065-1074.

Krakowski ML, Kritzik MR, Jones EM, Krahl T, Lee J, Arnush M, Gu D \& Sarvetnick N 1999 Pancreatic expression of keratinocyte growth factor leads to differentiation of islet hepatocytes and proliferation of duct cells. American Journal of Pathology 154 683-691.

Michel C, Chariot J, Souchard M \& Roze C 1982 Modifications of the endocrine pancreas in rats after ethionine destruction of acini. Cellular and Molecular Biology 28 135-148.

Morimoto S, Mendoza-Rodriguez CA, Hiriart M, Larrieta ME, Vital P \& Cerbon MA 2005 Protective effect of testosterone on early apoptotic damage induced by streptozotocin in rat pancreas. Journal of Endocrinology $187217-224$

Movassat J \& Portha B 1999 Beta-cell growth in the neonatal Goto-Kakizaki rat and regeneration after treatment with streptozotocin at birth. Diabetologia 42 1098-1106.

Movassat J, Saulnier C \& Portha B 1997 Insulin administration enhances growth of the B-cell mass in streptozotocin-treated newborn rats. Diabetes 46 1445-1452.

Movassat J, Beattie GM, Lopez AD, Portha B \& Hayek A 2003 Keratinocyte growth factor and beta-cell differentiation in human fetal pancreatic endocrine precursor cells. Diabetologia 46 822-829.

Plachot C, Movassat J \& Portha B 2001 Impaired beta-cell regeneration after partial pancreatectomy in the adult Goto-Kakizaki rat, a spontaneous model of type II diabetes. Histochemistry and Cell Biology 116 131-139. 
Portha B, Levacher C, Picon L \& Rosselin G 1974 Diabetogenic effect of streptozotocin in the rat during the perinatal period. Diabetes $\mathbf{2 3}$ 889-895.

Rubin JS, Osada H, Finch PW, Taylor WG, Rudikoff S \& Aaronson SA 1989 Purification and characterization of a newly identified growth factor specific for epithelial cells. PNAS 86 802-806.

Sadohara T, Sugahara K, Urashima Y, Terasaki H \& Lyama K 2001 Keratinocyte growth factor prevents ischemia-induced delayed neuronal death in the hippocampal CA1 field of the gerbil brain. Neuroreport $\mathbf{1 2}$ 71-76.

Sarvetnick N, Shizuru J, Liggitt D, Martin L, McIntyre B, Gregory A, Parslow T \& Stewart T 1990 Loss of pancreatic islet tolerance induced by beta-cell expression of interferon-gamma. Nature 346 844-847.

Senaldi G, Shaklee CL, Simon B, Rowan CG, Lacey DL \& Hartung T 1998 Keratinocyte growth factor protects murine hepatocytes from tumor necrosis factor-induced apoptosis in vivo and in vitro. Hepatology 27 584-591.

Sharma A, Zangen DH, Reitz P, Taneja M, Lissauer ME, Miller CP, Weir GC \& Bonner-Weir S 1999 The homeodomain protein IDX-1 increases after an early burst of proliferation during pancreatic regeneration. Diabetes $\mathbf{4 8}$ 507-513.

Terada T, Ohta T, Kitamura Y, Ashida K, Matsunaga Y \& Kato M 1997 Endocrine cells in intraductal papillary-mucinous neoplasms of the pancreas. A histochemical and immunohistochemical study. Virchows Archiv $43131-36$
Tourrel C, Bailbé D, Meile M, Kergoat M \& Portha B 2001 Glucagon-like peptide 1 and its long acting analog exendin-4 stimulates beta cell neogenesis in streptozotocin-treated newborn rats resulting in persistently improved glucose homeostasis at adult age. Diabetes 50 1562-1570.

Ulich TR, Yi ES, Longmuir K, Yin S, Biltz R, Morris CF, Housley RM \& Pierce GF 1994 Keratinocyte growth factor is a growth factor for type II pneumocytes in vivo. Journal of Clinical Investigation 93 1298-1306.

Werner S, Peters KG, Longaker MT, Fuller-Pace F, Banda MJ \& Williams LT 1992 Large induction of keratinocyte growth factor expression in the dermis during wound healing. PNAS $\mathbf{8 9}$ 6896-6900.

Yamamoto H, Uchigata Y \& Okamoto H 1981 Streptozotocin and alloxan induce DNA strand breaks and poly(ADP-ribose) synthetase in pancreatic islets. Nature 294 284-286.

Yi ES, Yin S, Harclerode DL, Bedoya A, Bikhazi NB, Housley RM, Aukerman SL, Morris CF, Pierce GF \& Ulich TR 1994 Keratinocyte growth factor induces pancreatic ductal epithelial proliferation. American Journal of Pathology 145 80-85.

Received in final form 31 July 2007

Accepted 15 August 2007

Made available online as an Accepted Preprint 16 August 2007 